\title{
Eficácia da estimulação elétrica com corrente russa após neurorrafia término-lateral do nervo fibular comum: análise eletroneuromiográfica e de força muscular
}

\author{
Efficacy of electrical Russian current stimulation after end-to-side neurorrbaphy of the \\ common fibular nerve: electroneuromyography and muscle strength analysis \\ Eficacia de la estimulación eléctrica con la corriente rusa tras la neurorrafia término-lateral \\ del nervio fibular común: análisis electroneuromiográfico y de fuerza muscular muscular \\ Mariana Moreno Gabira', Geraldo Marco Rosa Junior², Guilherme Eleutério Alcalde³, Cleber Ferraresi, \\ Luis Henrique Simionato ${ }^{5}$, Carlos Henrique Fachin Bortoluci ${ }^{6}$
}

\begin{abstract}
RESUMO I Lesões de nervos periféricos levam a perda funcional elevada no tecido muscular. Assim, muitas pesquisas têm investigado técnicas cirúrgicas, como neurorrafias, e recursos terapêuticos, como eletroestimulação, para melhorar a funcionalidade de um músculo reinervado após lesão periférica. Este estudo tem como objetivo investigar os efeitos da eletroestimulação com corrente russa $(2.500 \mathrm{~Hz}, 4 \mathrm{~ms}$, 10 seg. de contração por 20 seg. de relaxamento, modulação de $10 \mathrm{~Hz}$ e $100 \mathrm{~Hz}$ ) na recuperação funcional após secção e neurorrafia términolateral do coto distal do nervo fibular comum à face lateral do nervo tibial em ratos. Foram utilizados 25 ratos Wistar, machos, com 80 dias de vida, fornecidos pelo Biotério Central da Universidade Sagrado Coração (Bauru, SP, Brasil). Os animais foram divididos aleatoriamente em cinco grupos: grupo-controle Inicial (GCl), grupo-controle final (GCF), grupo experimental não tratado (GENT), grupo neurorrafia término-lateral com estimulação russa (GNTLER) e grupo-controle desnervado (GCD). A corrente russa foi iniciada cinco dias após neurorrafia e aplicada no músculo tibial cranial do GNTLER, 3 vezes por semana, totalizando 36 sessões. A estimulação elétrica foi eficaz para aumentar a amplitude e diminuir a latência do músculo reinervado, além de aumentar a força muscular
\end{abstract}

em comparação ao GCD. Diante disso, conclui-se que a eletroestimulação de média frequência (corrente russa) foi eficiente na recuperação funcional do músculo tibial cranial após neurorrafia término-lateral do nervo fibular comum.

Descritores | Estimulação Elétrica; Estimulação Elétrica Nervosa Transcutânea; Ratos Wistar; Nervo Fibular.

ABSTRACT I Peripheral nerve injury leads to a high functional loss of muscle tissue. Thus, many studies have investigated surgical techniques, such as neurorraphies, and therapeutic resources, such as electrical stimulation, to improve the functionality of reinnervated muscle after peripheral injury. This study aims to investigate the effects of electrical stimulation with Russian Current $(2,500 \mathrm{~Hz}, 4 \mathrm{~ms}, 10: 20 \mathrm{sec}$ contraction/relaxation, modulated at $10 \mathrm{~Hz}$ and $100 \mathrm{~Hz}$ ) in the functional recovery after section and end-to-side neurorrhaphy of the peroneal nerve distal stump common to the lateral face of the tibial nerve in rats. In this study, 25 male Wistar rats with 80 days of life were used, provided by the Universidade Sagrado Coração (USC), Bauru, SP, Brazil. The animals were randomly divided into five groups: Initial Control Group (ICG), Final Control Group (FCG), Untreated Experimental Group (UEG), End-to-Side Neurorrhaphy with Russian Stimulation Group (ENRSG), and Denervated

Universidade do Sagrado Coração (USC) - Bauru (SP), Brasil. E-mail: marianagabira17@gmail.com. Orcid: 0000-0003-1330-3740 2Universidade do Sagrado Coração (USC) - Bauru (SP), Brasil. E-mail: geraldo.junior@usc.br. Orcid: 0000-0003-1787-3396 3Universidade do Sagrado Coração (USC) - Bauru (SP), Brasil. E-mail: geafisio@hotmail.com. Orcid: 0000-0002-5505-4378 ${ }^{4}$ Universidade Brasil (UB) - São Paulo (SP), Brasil. E-mail: cleber.ferraresi@gmail.com. Orcid: 0000-0002-1361-8390 5Universidade do Sagrado Coração (USC) - Bauru (SP), Brasil. E-mail: ssimionato@terra.com.br. Orcid: 0000-0002-5603-6702 6Universidade do Sagrado Coração (USC) - Bauru (SP), Brasil. E-mail: carlos.fachin743@hotmail.com. Orcid:0000-0002-2613-4766 
Control Group (DCG). The Russian Current was started 5 days after neurorrhaphy and applied to the cranial tibial muscle of the ENRSG, 3 times a week, totaling 36 sessions. We observed that the electrical stimulation with Russian Current (ENRSG) was effective to increase amplitude ( $\mathrm{mV}$ ) and to decrease the latency (ms) of the reinnervated muscle, besides increasing the muscle strength when compared with the denervated control group. Therefore, we concluded that the average frequency electrical stimulation (Russian current) was efficient in the functional recovery of the cranial tibial muscle after the end-lateral neurorrhaphy of the common fibular nerve.

Keywords | Electric Stimulation; Transcutaneous Electric Nerve Stimulation; Rats, Wistar; Peroneal Nerve.

RESUMEN | Las lesiones de los nervios periféricos ocasionan una elevada pérdida funcional en el tejido muscular. De esta manera, en muchos estudios se han investigado técnicas quirúrgicas, como neurorrafias, y recursos terapéuticos, como la electroestimulación, para mejorar la funcionalidad del músculo reinervado tras una lesión periférica. El presente estudio tiene como objetivo investigar los efectos de la electroestimulación con corrente rusa $(2.500 \mathrm{~Hz}, 4 \mathrm{~ms}$,
10 seg. de contracción por 20 seg. de relajación, modulación de $10 \mathrm{~Hz}$ y $100 \mathrm{~Hz}$ ) en la recuperación funcional tras la sección y neurorrafia término-lateral del muñón distal del nervio fibular común en la parte lateral del nervio tibial en ratas. Se utilizaron 25 ratas Wistar, machos, con 80 días de vida, proporcionadas por el Biotério Central de la Universidade do Sagrado Coração (Bauru, SP, Brasil). Se dividieron aleatoriamente los animales en cinco grupos: grupo de control inicial $(\mathrm{GCl})$, grupo de control final (GCF), grupo experimental no tratado (GENT), grupo de neurorrafia término-lateral con estimulación rusa (GNTLER) y grupo de control denervado (GCD). La corriente rusa se inició cinco días tras la neurorrafia, siendo que la aplicó al músculo tibial craneal del GNTLER 3 veces a la semana, con un total de 36 sesiones. La estimulación eléctrica se mostró efectiva para aumentar la amplitud y disminuir la latencia del músculo reinervado, además de aumentar la fuerza muscular en comparación con el GCD. Por lo tanto, se concluye que la estimulación eléctrica de frecuencia media (corriente rusa) fue eficaz en la recuperación funcional del músculo tibial craneal tras la neurorrafia término-lateral del nervio fibular común.

Palabras clave | Estimulación Eléctrica; Estimulación Eléctrica Transcutánea del Nervio; Ratas Wistar; Nervio Fibular.

\section{INTRODUÇÃO}

A lesão nervosa periférica é comum na prática clínica da fisioterapia, sendo complexa e pouco explorada cientificamente. $\mathrm{O}$ comprometimento na transmissão dos impulsos nervosos é uma das consequências desse tipo de lesão e produz diversas alterações no sistema muscular, como atrofia ${ }^{1,2}$.

Relacionadas com o envolvimento anatômico, as lesões no nervo periférico são classificadas em três tipos: neuropraxia, caracterizada por bloqueio localizado da condução elétrica, sem interrupção da continuidade axonal ou degeneração; axonotmese, em que ocorre ruptura na continuidade do axônio, porém os tubos endoneurais permanecem intactos; e neurotmese, em que ocorre ruptura de uma ou mais camadas de tecido conectivo do nervo ${ }^{2,3}$.

Dentre as técnicas de reparo microcirúrgico em nervos, destaca-se a neurorrafia término-lateral (NTL), que consiste na coaptação de um segmento de nervo lesado na superfície lateral de outro nervo íntegro adjacente, restabelecendo características fisiológicas ${ }^{4}$. No estudo de Viterbo et al. ${ }^{5}$ foi realizada secção do nervo fibular, que inerva o músculo tibial cranial. Seu coto distal foi suturado à face lateral do nervo tibial intacto, sem a remoção do epineuro. Assim, pela primeira vez, obtevese reinervação muscular sem prejuízo ao nervo doador, o que representou uma valiosa contribuição, pois a partir dessa técnica cirúrgica qualquer nervo pode ser utilizado como nervo doador.

A estimulação elétrica com finalidade regenerativa tornou-se objeto de estudo na recuperação funcional pois tem sido utilizada como recurso terapêutico para prevenir atrofia muscular e, em alguns casos, evitar a perda de tecido muscular resultante de períodos de inatividade ou de desnervação $0^{6,7}$. Utilizada nesse tipo de eletroestimulação, a corrente russa é uma corrente alternada, com frequência na faixa de $2.500 \mathrm{~Hz}$ e duração de pulso de 4 milissegundos, indicada para lesões nervosas periféricas e considerada uma alternativa eficaz e segura ${ }^{8}$.

Estudos prévios demonstram a efetividade da eletroestimulação na regeneração nervosa. No entanto, ainda não são conhecidos estudos que investigam os efeitos da eletroestimulação com corrente russa na recuperação funcional de lesões nervosas periféricas após neurorrafias. A hipótese deste estudo é que a eletroestimulação de média frequência com corrente russa pode ter um efeito benéfico na recuperação funcional do músculo 
tibial cranial desnervado de ratos Wistar submetidos a neurorrafia. Assim, buscou-se investigar os efeitos da eletroestimulação com corrente russa na recuperação funcional após secção e neurorrafia término-lateral do coto distal do nervo fibular comum à face lateral do nervo tibial em ratos Wistar.

\section{METODOLOGIA}

\section{Aleatorização}

Foram utilizados 25 ratos (Rattus norvegicus) da linhagem Wistar, machos, com 80 dias de vida, divididos aleatoriamente em cinco grupos: (1) grupo-controle inicial (GCI); (2) grupo-controle final (GCF); (3) grupo experimental não tratado (GENT); (4) grupo neurorrafia término-lateral com estimulação russa (GNTLER); e (5) grupo-controle desnervado (GCD). Os animais do GCI, GCF, GENT, GNTLER e GCD foram sacrificados com 90 dias após o início do experimento.

\section{Cirurgia}

Os animais foram mantidos em caixas apropriadas, forradas com maravalha, em temperatura controlada $\left(25 \pm 2^{\circ} \mathrm{C}\right)$, com ciclo claro-escuro de 12 horas e ração e água ad libitum até o momento da eutanásia. Para cada procedimento cirúrgico, os animais foram anestesiados com ketamina $(80 \mathrm{mg} / \mathrm{kg})$ e xilasina $(10 \mathrm{mg} / \mathrm{kg})$ via intraperitoneal.

Os procedimentos foram realizados por um único pesquisador, a fim de garantir fidedignidade e padronização, com auxílio de um microscópio cirúrgico DF Vasconcelos, com aumento de 10 a 16 vezes. Após o procedimento, a incisão foi suturada por planos com pontos simples, utilizando fio monofilamentar de náilon 4-0 na musculatura e pele dos animais.

Após o procedimento, os animais foram observados, tendo sua dor avaliada pelos seguintes sinais: vocalização, piloereção, postura encurvada, hipotermia, descarga ocular, ato de se lamber, maior agressividade, relutância em interagir, alteração no consumo de água e alimentos e perda de peso. Foi usado analgésico até não haver mais sinais de dor. A analgesia pós-operatória foi realizada com acetominofeno (paracetamol) $2 \mathrm{mg} / \mathrm{mL}$ adicionado à água do bebedouro.

\section{Protocolo de eletroestimulação}

A eletroestimulação teve início cinco dias após a cirurgia. Os animais do grupo GNTLER foram submetidos a três sessões semanais durante 90 dias, totalizando 36 sessões. Esses animais receberam estimulação elétrica no músculo tibial cranial com corrente russa na frequência de $2.500 \mathrm{~Hz}$, sincronizada, com duração de 4 milissegundos de duração de pulso, tempo de contração de 10 segundos por 20 segundos de relaxamento e duração total de 20 minutos.

Foi utilizado um estimulador elétrico Endophasys $\mathrm{KLD}^{\varpi}$, e a corrente inicial foi aquela suficiente para promover a contração muscular. Os animais foram estimulados acordados e sem anestesia. Para isto, foram colocados dentro de uma cápsula metálica com abertura posterior para a cauda e duas aberturas laterais para fixação dos membros posteriores. Após a imobilização, eletrodos autoadesivos de $1 \mathrm{~cm}^{2}$ foram fixados sobre o ventre do músculo.

\section{Medidas avaliativas}

As medidas avaliativas de eletroneuromiografia e força muscular foram tomadas imediatamente após o protocolo de eletroestimulação do GNTLER, exceto para o GCI, cujas medições foram realizadas na primeira semana do estudo.

\section{Eletroneuromiografia}

Para o teste eletrofisiológico, realizado antes da eutanásia dos animais, a temperatura ambiente foi mantida em $25^{\circ} \mathrm{C}$. Após anestesia com ketamina $(80 \mathrm{mg} / \mathrm{kg})$ e xilasina $(10 \mathrm{mg} / \mathrm{kg})$ intramuscular, os animais foram imobilizados em decúbito ventral. Foram realizadas tricotomia e ampla incisão no membro posterior previamente operado, permitindo acesso aos nervos isquiático e fibular comum. O potencial de ação composto foi registrado por eletrodos de agulha ativo e de referência.

O eletrodo vermelho (referência) foi colocado no tendão do músculo tibial cranial; o eletrodo preto (ativo), no ventre do músculo tibial cranial; e o eletrodo verde (dispersivo), em local distante da região estudada (Figura 1). 


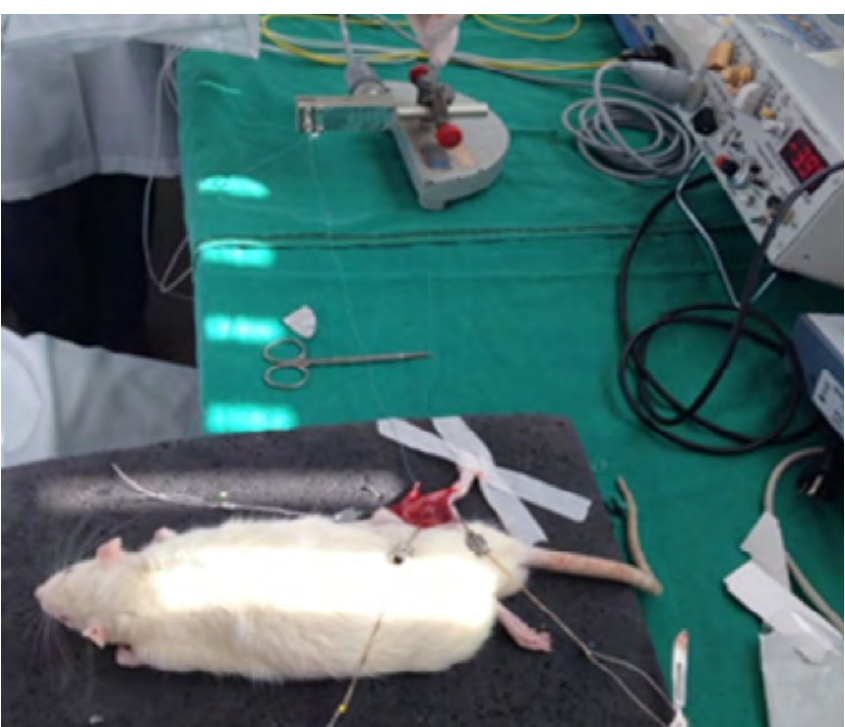

Figura 1. Análise da força muscular

Os eletrodos registraram a duração, a amplitude e a latência do potencial de ação muscular. Foram realizados três conjuntos de medidas para cada animal com o nervo tibial intacto, e mais três com a porção do nervo tibial seccionado distalmente à neurorrafia término-lateral (NTL), sendo escolhido um conjunto com o nervo tibial intacto e um conjunto com o nervo tibial seccionado. Foram selecionados os conjuntos de maior amplitude registrada. Os dados de amplitude e latência foram comparados entre os grupos. Foi utilizado o eletromiógrafo Sapphire II $4 \mathrm{ME}^{\circledast}$.

\section{Avaliação da força muscular}

Após o teste eletrofisiológico, o tendão distal do músculo tibial cranial foi seccionado e acoplado a um transdutor de força (FT03, Grass Technologies), usando sutura com fio de náilon 4-0. O músculo foi tracionado pelo fio de náilon, aumentando seu comprimento até que esta tração determinasse uma tensão com carga de $0,18 \mathrm{~N}$. Este valor de pré-tensionamento foi determinado durante a calibração do dispositivo e reajustado entre os testes.

Os eletrodos do estimulador elétrico foram posicionados diretamente no músculo tibial cranial exposto. $\mathrm{O}$ ensaio de contração muscular foi realizado em três aplicações sequenciais de um segundo na mesma corrente utilizada no tratamento dos animais do grupo GNTLER. Um computador registrou os picos de força. A tensão muscular foi reajustada entre as medições. O teste de contração tetânica foi realizado com 100 miliamperes e variação de frequência de $10 \mathrm{~Hz}$ e $100 \mathrm{~Hz}$ (Figura 2).

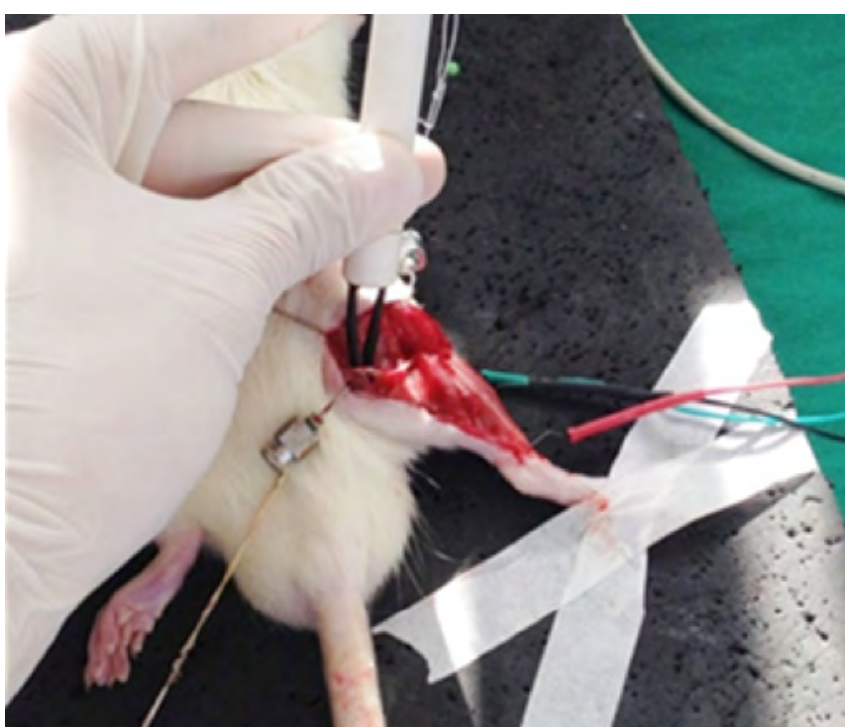

Figura 2. Eletroneuromiografia

\section{Análise estatística}

A normalidade dos foi avaliada pelo teste de ShapiroWilk. Os grupos foram comparados por análise de variância de fator único (Anova one-way), e post hoc de Tukey para as comparações múltiplas. Foi considerado resultado significativo $p \leq 0,05$. Utilizou-se na análise o software GraphPad Prisma 5.2.

\section{RESULTADOS}

\section{Amplitude}

As médias dos resultados de amplitude (milivolt $[\mathrm{Mv}]$ ), aferidas por meio de eletroneuromiografia, podem ser observadas na Figura 3.

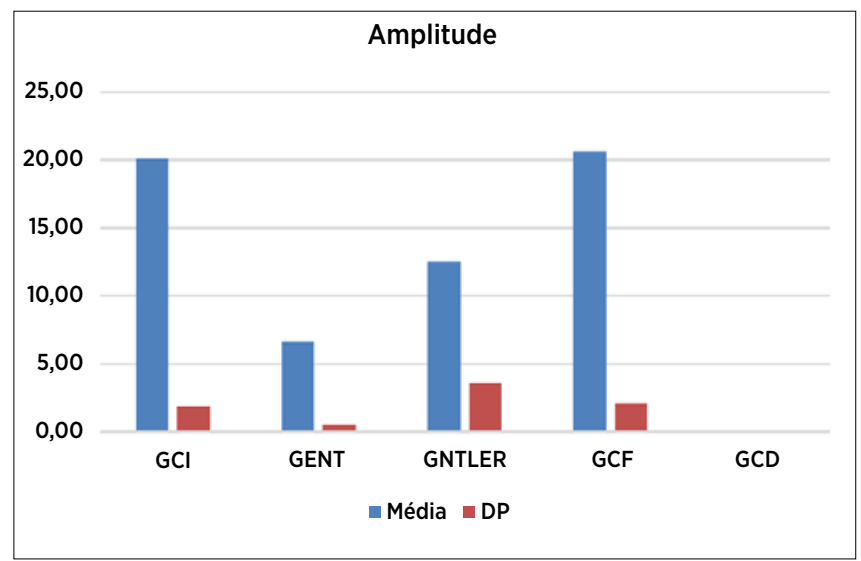

Figura 3. Média e desvio-padrão da amplitude ( $\mathrm{mV}$ ) aferidos por eletroneuromiografia

GCl: grupo-controle inicial; GENT: grupo experimental não tratado; GNTLER: grupo neurorrafia término-lateral com estimulação russa; GFC: grupo-controle final; GCD: grupo-controle desnervado. 
A média da amplitude do GNTLER foi maior e apresentou diferença significativa $(\mathrm{p}=0,05)$ em comparação com o GENT. Os grupos GCI e GCF não apresentaram diferenças estatísticas $(\mathrm{p}=0,05)$ entre eles. No entanto, o grupo GNTLER apresentou menor amplitude significativa quando comparado aos grupos GCI ( $\mathrm{p}=0,05)$ e GCF $(\mathrm{p}=0,05)$.

\section{Latência}

As médias dos resultados de latência (milissegundo [ms]), também aferidas por eletroneuromiografia, são observadas na Figura 4.

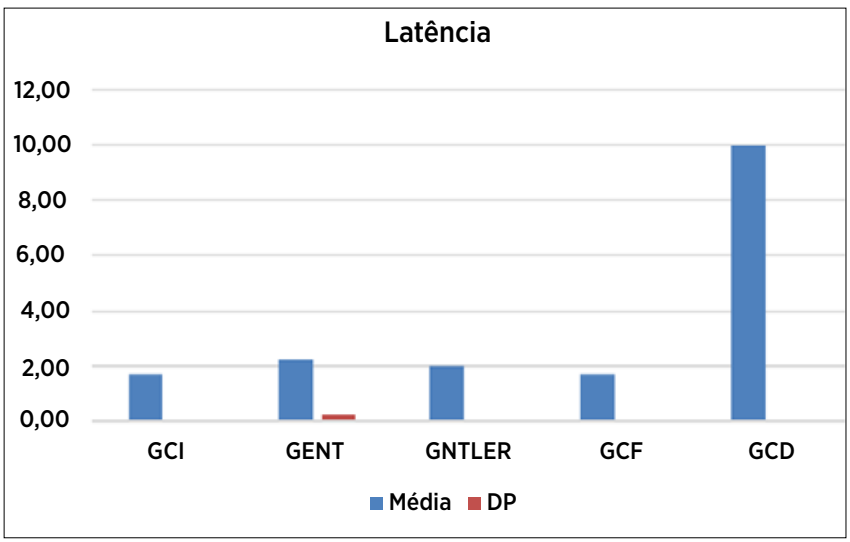

Figura 4. Média e desvio-padrão da latência (ms) aferidos por eletroneuromiografia

GCl: grupo-controle inicial; GENT: grupo experimental não tratado; GNTLER: grupo neurorrafia término-lateral com estimulação russa; GFC: grupo-controle final; GCD: grupo-controle desnervado.

A média da latência do GNTLER foi menor e apresentou diferença significativa $(\mathrm{p}=0,05)$ em comparação com o GENT. Os grupos GCI e GCF não apresentaram diferenças estatisticamente significativas. Por fim, o grupo GNTLER apresentou maior latência quando comparado aos grupos GCI ( $p=0,05)$ e GCF (p=0,05).

\section{Força muscular (N)}

As médias de força muscular, aferidas com transdutor de força (FT03, Grass Technologies), são observadas na Figura 5.

Observa-se que a média dos resultados da força muscular não apresentou diferença significativa na comparação entre GNTLER e GENT. Os grupos GCI e GCF apresentaram diferenças significativas $(p=0,05)$ entre $\mathrm{si}$, as quais podem ser justificadas pelo crescimento dos animais. Pode-se notar também que o grupo GNTLER apresentou menor força muscular quando comparado aos grupos GCI $(p=0,05)$ e GCF $(p=0,05)$.

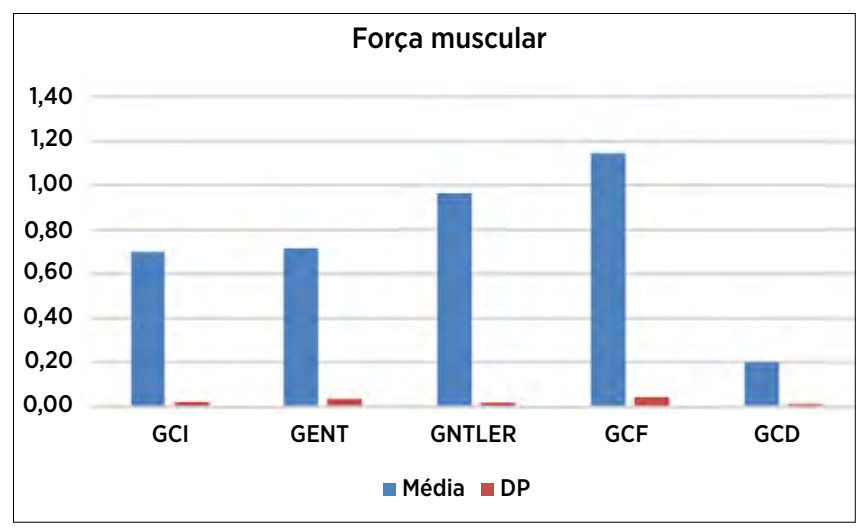

Figura 5. Média e desvio-padrão da força muscular

GCl: grupo-controle inicial; GENT: grupo experimental não tratado; GNTLER: grupo neurorrafia término-lateral com estimulação russa; GFC: grupo-controle final; GCD: grupo-controle desnervado.

\section{DISCUSSÃO}

Considerando os resultados de eletroneuromiografia e força muscular, verificou-se neste estudo que a eletroestimulação de média frequência (corrente russa) foi eficaz na recuperação funcional de ratos Wistar submetidos a seç̧ão e neurorrafia término-lateral do coto distal do nervo fibular comum à face lateral do nervo tibial.

É notável que a neurorrafia término-lateral alcança resultados clinicamente satisfatórios, pois sua eficácia nos resultados tem levado profissionais a utilizarem-na em ensaios clínicos, sendo importante o embasamento técnico, teórico e científico através de estudos experimentais em animais ${ }^{9}$. No entanto, apenas a neurorrafia término-lateral não foi capaz de restabelecer os valores iniciais da força muscular dos animais (Figura 5).

A eletroneuromiografia estuda o sistema nervoso periférico e muscular, avaliando a integridade funcional dos neurônios motores periféricos e sensitivos, das placas mioneurais e dos músculos. Trata-se de exame complementar, que permite avaliar, por exemplo, a intensidade da lesão durante o teste eletrofisiológico ${ }^{10,11}$.

O teste eletrofisiológico fornece dados de latência e amplitude. A latência traduz-se na condução nervosa, ou seja, no número de fibras mielinizadas. Já a amplitude informa o número de fibras musculares que respondem ao estímulo elétrico e, consequentemente, o número de axônios excitáveis ${ }^{12}$. Nesse contexto, a neurorrafia término-lateral associada à eletroestimulação com corrente russa (GNTLER) foi superior à neurorrafia isolada (GENT) e ao grupo sem reparo nervoso (GCD), aumentando o número de fibras musculares excitáveis eletricamente (maiores amplitudes em $\mathrm{mV}$ ) (Figura 3). Ainda, considerando a latência, o grupo GNTLER 
apresentou resultados muitos similares aos grupos $\mathrm{GCI}$ e GCF, sugerindo melhor condução nervosa (Figura 4).

A estimulação elétrica com corrente russa consiste em uma corrente de média frequência, de $2.500 \mathrm{~Hz}$, modulada para $50 \mathrm{~Hz}$. Essa corrente produz 50 pulsos polifásicos por segundo, com repetição de disparo de $50 \mathrm{~Hz}$ e duração de 400 milissegundos entre cada pulso, ou seja, dentro da faixa de alcance biológico de estímulo (entre $0,1 \mathrm{~Hz}$ e $200 \mathrm{~Hz}$ ), o que torna a estimulação relativamente confortáve ${ }^{13}$.

Em estudo de Maciel et al. ${ }^{14}$ foram utilizados ratos submetidos a neurorrafia término-lateral, que receberam eletroestimulação com uma corrente de $1 \mathrm{KHz}$. O grupo que recebeu a eletroestimulação obteve melhora mais significativa do índice funcional do fibular em comparação com o grupo não estimulado, $60,5 \%$ e $9,5 \%$, respectivamente. $\mathrm{O}$ aumento da força muscular foi outro fator que contribuiu para a melhora funcional, sendo que o grupo experimental estimulado obteve resultado estatisticamente significativo quando comparado ao grupo não estimulado.

No experimento de Willand et al..$^{15}$, o nervo isquiático de ratos foi seccionado, e o reparo da lesão foi adiado por diferentes períodos. A estimulação elétrica foi aplicada tardiamente para promover regeneração, 24 semanas após reparos nervosos. No entanto, resultados recentes mostram que o período mais efetivo para se realizar a estimulação elétrica é de até um mês após o reparo nervoso.

O presente estudo corrobora esses resultados prévios, da neurorrafia até o início da eletroestimulação. Mas é importante salientar que, apesar dos bons resultados obtidos nesta pesquisa, a literatura ainda carece de estudos para estabelecer protocolos ideais de tratamento de lesões nervosas periféricas. Nesse sentido, outros recursos, como laserterapia ou fototerapia (fotobiomodulação), também têm sido investigados ${ }^{16,17}$.

Por fim, conclui-se que o modelo experimental de neurorrafia término-lateral do nervo fibular comum, associado à eletroestimulação com corrente russa, foi eficaz na recuperação funcional de ratos, contribuindo para futuros estudos e para a prática clínica da reabilitação.

\section{Limitação}

Neste estudo avaliou-se a recuperação funcional do músculo desnervado por meio de força muscular, amplitude $(\mathrm{mV})$ e latência (ms), mas a marcha também poderia ser utilizada em estudos futuros. Além disso, sugere-se investigar os efeitos da eletroestimulação com corrente russa por períodos maiores que 12 semanas (36 sessões).

\section{CONCLUSÃO}

Com base no modelo experimental deste estudo, pôdese concluir que a eletroestimulação de média frequência (corrente russa) foi eficiente na recuperação funcional do músculo tibial cranial desnervado, considerando a amplitude e a latência do músculo após neurorrafia término-lateral.

\section{REFERÊNCIAS}

1. Cavalcante VEV, Montenegro EJN, Pontes NTF. Efeito da eletroestimulação no músculo desnervado de animais: revisão sistemática. Fisioter Mov. 2012;25(3):669-78. doi: 10.1590/ S0103-51502012000300022

2. Viterbo F. Neurorrafia látero-terminal: estudo experimental no rato [tese]. Botucatu (SP): Universidade Estadual Paulista; 1992.

3. Rovak JM, Cederna PS, Kuzon WM. Terminolateral neurorrhaphy: a review of the literature. J Reconstr Microsurg. 2001;17(8):61524. doi: 10.1055/s-2001-18817

4. Souza FI, Santos GB, Silva CF, Mattar Júnior R, Zumiotti AV. Avaliação histológica da neurorrafia término-lateral: estudo experimental em ratos. Acta Ortop Bras. 2011;19(3):129-31. doi: 10.1590/S1413-78522011000300002

5. Viterbo F, Trindade JC, Hoshino K, Mazzoni Neto A. Lateroterminal neurorrhaphy without removal of the epineural sheath: experimental study in rats. Rev Paul Med. 1992;110(6):267-75. doi: 10.1590/S1516-31801998000500005

6. Carvalho DCl, Rosim CG, Gama LOR, Tavares MR, Tribioli RA. Tratamentos não farmacológicos na estimulação da osteogênese. Rev Saúde Pública. 2002;36(5):647-54. doi: 10.1590/S0034-89102002000600017

7. Viterbo F, Trindade JC, Hoshino K, Mazzoni Neto A. Endto-side neurorraphy with removal of the epineurial sheath: an experimental study in rats. Plastic Reconstruc Surg. 1994;94(7):1038-47. doi: 10.1590/s0102-865020170090000002

8. Ward AR, Lucas TS. Lowering of sensory, motor and paintolerance thresholds with burst duration using $\mathrm{kHz}$ frequency alternating current electrical stimulation. Arch Phys Med Rehabil. 2007;88(8):1036-41. doi: 10.1016/j.apmr.2007.04.009

9. Papalia I, Ronchi G, Muratori L, Mazzucco A, Magaudda L, Geuna S. Direct muscle neurotization after end-to end and end-to-side neurorrhaphy: an experimental study in the rat forelimb model. Neural Regen Res. 2012;7(29):2273-8. doi: 10.3969/j.issn.1673-5374.2012.29.005

10. Udina E, Puigdemasa A, Navarro X. Passive and active exercise improve regeneration and muscle reinnervation after peripheral nerve injury in the rat. Muscle Nerve. 2011;43(4):500-9. doi: 10.1002/mus.21912

11. Thompson NJ, Sengelaub DR, English AW. Enhancement of peripheral nerve regeneration due to treadmill training and electrical stimulation is dependent on androgen receptor signaling. Dev Neurobiol. 2014;74(5):531-40. doi: 10.1002/ dneu. 22147 
12. Nemeth PM. Electrical stimulation of denervated muscle prevents decreases in oxidative enzymes. Muscle Nerve. 1982;5(2):134-9. doi: 10.1002/mus.880050210

13. Viterbo F, Trindade JC, Hoshino K, Mazzoni Neto A. Two endto side neurorraphies and nerve graft with removal of the epineural sheath: experimental study in rats. Br J Plastic Surg. 1994;47(2):75-80. doi: 10.1590/S0102-86502012000300010

14. Maciel FO, Viterbo F, Chinaque LDFC, Souza BM. Effect of electrical stimulation of the cranial tibial muscle after end-toside neurorrhaphy of the peroneal nerve in rats. Acta Cir Bras. 2013;28(1):39-47. doi: 10.1590/S0102-86502013000100007

15. Willand MP, Chiang CD, Zhang JJ, Kemp SWP, Borschel $\mathrm{GH}$, Gordon T. Daily electrical muscle stimulation enhances functional recovery following nerve transection and repair in rats. Neurorehabil Neural Repair. 2015;29(7):690-700. doi: 10.1177/1545968314562117

16. Rosso MPO, Rosa Júnior GM, Buchaim DV, German IJS, Pomini KT, Souza RG, et al. Stimulation of morphofunctional repair of the facial nerve with photobiomodulation, using the end-to-side technique or a new heterologous fibrin sealant. J Photochem Photobiol B. 2017;175:20-8. doi: 10.1016/j.jphotobiol.2017.08.023

17. Buchaim DV, Andreo JC, Ferreira Junior RS, Barraviera B, Rodrigues AC, Macedo MC, et al. Efficacy of laser photobiomodulation on morphological and functional repair of the facial nerve. Photomed Laser Surg. 2017;35(8):442-9. doi: 10.1089/pho.2016.4204 